\title{
EFFICIENCY IMPROVEMENT OF FOREST MACHINERY EXPLOITATION
}

\author{
Igor GRIGOREV ${ }^{1}$, Ol'ga KUNICKAYA ${ }^{1}$, Alexey PROSUZHIH ${ }^{2}$, Igor KRUCHININ ${ }^{3}$, \\ Dmitry SHAKIRZYANOV ${ }^{4}$, Viktoria SHVETSOVA ${ }^{5}$, Oleg MARKOV ${ }^{6}$, Sergey EGIPKO $^{7}$ \\ ${ }^{1}$ Department of Technology and Equipment of Forest Complex, Yakut State Agricultural Academy, Yakutsk, \\ Russian Federation, grigorevigo1@ rambler.ru \\ ${ }^{2}$ Department of Logging Technology and Machines, Ukhta State Technical University, Ukhta, Russian \\ Federation \\ ${ }^{3}$ Department of Transport and Road Construction, Ural State Forestry University, Ekaterinburg, Russian \\ Federation \\ ${ }^{4}$ Department of Engineering of Technological Machines and Equipment, Ukhta State Technical University, \\ Ukhta, Russian Federation \\ ${ }^{5}$ Department of Descriptive Geometry and Engineering Graphics, Saint-Petersburg State University Architecture \\ and Civil Engineering, Saint-Petersburg, Russian Federation \\ ${ }^{6}$ Department of General Technical Subjects, Federal State Budget Educational Institution of Higher Education \\ "Petrozavodsk State University", Petrozavodsk, Russian Federation \\ ${ }^{7}$ Department Machines Environmental Engineering, Don State Agrarian University, Novocherkassk, Russian
} Federation

\begin{abstract}
The purpose of this work was to develop a model of the interaction process between the wheeled forwarder and the soil of the cutting area, which allows evaluating the influence of soil conditions, the parameters of the wheeled forwarder, as well as load and number of cycles of its application, on the indicators of resistance and adhesion of the forwarder to the traction surface. Modeling results for 3- and 4-axle forest machines with different load levels showed that for different soil categories, types of bodies, and tire sizes. The results of the approximation analysis enabled the derive of calculation formulas for estimating the propulsive coefficient and rut depth after the first passage depending on the values of load-bearing capacity, body load coefficient, wheel width, and soil deformation module. The proposed model can be used at laying down the skidding roads and its optimization not only in economic terms but also with respect to the environment as intensive harvesting operations lead to extensive soil destructions. The practical application of the results is expressed in increased performance capacities of wood skidding operations and minimization of costs for restoring the productivity of forest area.
\end{abstract}

Keywords: forest harvesting, load-carrying capacity of the vehicles, skidding, soil, wheels adhesion.

\section{INTRODUCTION}

Forest operations are known to cause severe soil disturbance and erosion and have been the subject of numerous studies. In particular, logging with tractors leads to soil compaction $[1,2]$ and rutting, and is a major reason of soil surface degradation caused by human activities [3, 4]. The pressure exerted by loaded vehicles moving through the forest is a major factor causing compaction and rut formation [5]. In recent decades, the weight of forest machines has increased, raising new issues of concern in forest soil degradation [6, 7]. Skidding trails are usually forest areas subjected to compaction and waterlogging. The roadway in logging areas is usually poorly drained and not subjected to natural compaction, which results in the soil porosity reduction, infiltration of water and gas exchange, as well as increased soil erosion, waterlogging, and mudflows [8,9]. In almost all cases, the timber skidding operation has limited productivity within the whole technological chain of the mechanized harvesting system. Skidding performance depends on a large number of factors. Among others, a key role plays average skidding distance, the traffic load of the skidding equipment, and the speed (velocity) of its movement. Possible traffic load and the speed of skidding machinery depend in turn on the technical characteristics of skidding tractors and operating conditions such as soil, ground, and terrain conditions [10-12].

Noteworthy to mention that skidding performed by tractors is the most environmentally harmful operation for the forest ecosystems. Its negative environmental impact is expressed in severe destruction of soil horizons such as rutting and compaction, followed by subsequent processes of waterlogging, ravine formation, and decreased fertility of forest sites [13-15]. 
In this regard, the traffic load and forwarder speed need to be limited not only for operational efficiency reasons - cross-country ability and reliability, but also for ecological efficiency reasons - so that the subsequent costs of restoring the productivity of the forest area (reforestation work) do not exceed the momentary income from high productivity [16-18].

With the mechanization of logging operations, numerous studies were performed on improving the performance parameters of the skidding process and in particular forest machines and its trafficability. Enhanced performance of forest machinery and modification of skidding processes in different soil conditions remains a significant concern. One of the most important issues is the interaction between forest mechanized equipment with the forest soils [19-21].

Analytical description of the processes related to the movement of machinery on the soil and ground surfaces over the logging sites is much more difficult than that of the roads with a hard surface. Mechanical properties of soil-covered sites are very variable and unstable, the deformation mechanics is complicated, and has not been fully studied so far [22-24].

The purpose of this study was mathematical modeling of the interaction process between wheeled forwarder with and the soil of the cutting area. This model allows evaluating the influence of soil conditions, the parameters of the wheeled forwarder, as well as load and number of cycles of its application, on the indicators of resistance and adhesion of the forwarder to the traction surface. The testing of the wheeled forwarder's performance model is performed taking into account the technical characteristics of modern John Deere, Rottne, Ponsse, Komatsu, and Amkador forestry machines and various soil categories. The results of this study allow performing numerical analysis of the wheeled forwarder's traffic capacity and an assessment of the rut depth after the passage under certain conditions that have not only scientific value but also great potential in practical application

Translated with www.DeepL.com/Translator (free version)

\section{MATERIALS AND METHODS}

\subsection{The methodology for evaluating wheeled forwarder's productivity}

Currently, wheeled skidders of several companies are being utilized in Russia. These are John Deere, Rottne, Ponsse, Komatsu, and Amkodor. All models are all-wheels-driving and available with three (six wheels), four (eight wheels), and five (ten wheels) axles.

When determining the maximum volume of skidded timber, the following points should be considered [25]:

1. Load capacity limit of the machine.
2. Tangential traction force limit of the machine (tractive resistance of the vehicle should not exceed the maximum pulling force of the forwarder).

3. The limit of the forwarder's adhesion to the ground (tangential traction force should not exceed the force of the forwarder's adhesion to the soil of the harvesting area).

Moreover, it is recommended to set the weight limits for the skidder loading based on the allowable track depth after the first passage of the forwarder [26], which is considered to be no deeper than $10 \mathrm{~cm}$. This statement is supported by the studies on track development at the cyclic operation of grapples, i.e., multiple passes of the forwarder over the same trail sections. This raises the question of the forwarder's performance in skidding operations concerning the track depth limit.

The output per shift for each forwarder is determined by a formula:

$$
O_{C M}=\frac{3600 \varphi_{1} T_{S} Q}{\frac{l_{A V}}{U_{U}}+t_{M}+t_{W T}+\frac{Q}{Q_{P}} t_{C D}+\frac{l_{S V}}{U_{L}}},
$$

where $\varphi_{1}$ is the coefficient of operations per shift, $T_{S}$ is the shift duration, $Q$ is the volume of a bunch skidded by the forwarder, $l_{A V}$ is an average skidding distance, $t_{M}$ is maneuvering time in the harvesting area, $t_{W T}$ is the time for changing the equipment from transport to operational mode vice versa, $Q_{P}$ is the volume of wood taken and loaded into the load box by a harvesting arm at one go, $t_{C D}$ is the time for clam delivery to wood assortment, their capture and stacking into the forming device, $U_{U}$ is the speed of an unloaded skidder, and $U_{L}$ is the speed of a loaded skidder.

The ability of the vehicle to move with the limit of tractive force is determined from a well-known ratio [27]:

$$
T \geq F_{R},
$$

where $T$ is the traction force; $F_{R}$ is the total tractive resistance force. In technical calculations, the tractive resistance force is determined as follows [27]:

$$
F_{R}=\phi_{R} \cdot(G+Q \rho g),
$$

where $\varphi_{R}$ is the traction resistance coefficient of the vehicle, $G$ is the weight of the vehicle, $\rho$ is bulk density of the wood, and $g$ is a free-fall acceleration.

The speed and productivity of forest machinery is commonly calculated based on approximate values of traction resistance. These values are presented in Tables 1 and 2 .

Noteworthy, the values of the traction resistance are given in Tables 1 and 2 regardless of the machinery weight. At that, some studies [27,30] describe the nonlinear nature of the change in the traction resistance force of the machine depending on its weight. This indicates that the given coefficient is not a constant value for a particular terrain type. 
Table 1. Traction resistance coefficient $\varphi_{R}$ of grapple forest machines [27]

\begin{tabular}{|c|c|}
\hline $\begin{array}{r}\text { Type and condition of } \\
\text { the road } \\
\text { (bearing surface) }\end{array}$ & $\varphi_{R}$ \\
\hline Asphalt & $0.010 \ldots 0.020$ \\
\hline Concrete & $0.008 \ldots 0.015$ \\
\hline Gravel & $0.020 \ldots 0.025$ \\
\hline Crushed stone & $0.020 \ldots 0.030$ \\
\hline Top-soil & \\
\hline dry & $0.025 \ldots 0.035$ \\
\hline after the rain & $0,050 \ldots 0,150$ \\
\hline flooded & $0.150 \ldots 0.250$ \\
\hline dry sand & $0.100 \ldots 0.300$ \\
\hline Plank road & $0.020 \ldots 0.030$ \\
\hline Forest summer trail & \\
\hline & $0.080 \ldots 0.120$ \\
\hline wet & $0.100 \ldots 0.150$ \\
\hline waterlogged & $0.300 \ldots 0.400$ \\
\hline Forest winter trail & \\
\hline rolled & $0.050 \ldots 0.100$ \\
\hline unrolled & $0.150 \ldots 0.250$ \\
\hline dry & $0.040 \ldots 0.060$ \\
\hline Snowbound & \\
\hline rolled & $0.030 \ldots 0.050$ \\
\hline unrolled & $0.150 \ldots 0.250$ \\
\hline ice-coated & $0.020 \ldots 0.030$ \\
\hline Terrain in snow & $0.100 \ldots 0.300$ \\
\hline Ice-coated & $0.015 \ldots 0.030$ \\
\hline
\end{tabular}

Table 2. Traction resistance coefficient $\varphi_{R}$ of grapple forest machines on the trail [27]

\begin{tabular}{|r|r|}
\hline Traction surface & $\varphi_{R}$ \\
\hline rolled & $0.07-0.18$ \\
\hline unrolled & $0.10-0.25$ \\
\hline soft & - \\
\hline mellow & - \\
\hline
\end{tabular}

With a known value of the traction resistance $\varphi_{R}$, the speed of machine $U_{U}$ and $U_{L}$ can be calculated as follows:

$$
\begin{gathered}
U_{U}=\frac{N \cdot \eta}{\phi_{C} \cdot G}=\frac{N \cdot \eta}{F_{U F}}, \\
U_{L}=\frac{N \cdot \eta}{\phi_{R} \cdot(G+Q \rho g)}=\frac{N \cdot \eta}{F_{L F}},
\end{gathered}
$$

where $\eta$ is the transmission efficiency, $N$ is engine power, $F_{L F}$ and $F_{U F}$ are the values of the traction resistance force of loaded and unloaded forwarder, respectively.

The adhesion limit is defined as follows [27]:

$$
F_{A D} \geq F_{R},
$$

The adhesion force for all-wheel-drive forwarders is accepted to calculate as:

$$
F_{A D}=\phi_{A D} \cdot(G+Q \rho g) \text {, }
$$

where $\varphi_{A D}$ is the coefficient of the forwarder's adhesion to the surface of movement. This coefficient is believed to vary within the range 0.30.6 for wheeled vehicles [27].

\subsection{Evaluation of the forwarder's traction resistance force}

The influence of soil conditions on the performance of wheeled forwarders was examined based on soil classification by its mechanical properties offered in [32]. According to this classification, physical and mechanical properties of the soil can be expressed with satisfactory accuracy through the deformation module $E$ as follows:

$$
\begin{gathered}
C_{0}=10.774 E^{0.7737} \\
\phi_{0}=13.669 E^{0.1818} \\
\gamma=8.4008 E^{0.1168} \\
H=0.4714 E^{-0.479} \\
v=0.242 E^{-0.422}
\end{gathered}
$$

where $E$ is the soil deformation module, $C_{0}$ is internal adhesion, $\varphi_{0}$ is internal friction angle, $\gamma$ is volume weight of soil in natural compaction, $H$ is the thickness of the deformed layer (depth of compression strain expansion), and $v$ is Poisson's coefficient of the soil.

Considering that the shear module $E_{l}$ is calculated by formula [34]:

$$
E_{1}=\frac{E}{2(1+v)}
$$

and using equation (12), follows that:

$$
\begin{aligned}
E_{1}=\frac{E^{1.422}}{2 E^{0.422}+0.484} & \\
& \approx 0.4259 E
\end{aligned}
$$

The deformation module follows by default as [28]:

$$
E=\sigma / \varepsilon,
$$

where $\sigma$ is the normal operational stress and $\varepsilon$ is the relative deformation. Relative deformation $\varepsilon$ is the sum of reversible (elastic) and irreversible (plastic) deformations.

The variability of compression stress by soil depth is described by the quadratic equation [28]:

$$
\sigma=J q /\left\lfloor 1+(z / a b)^{2}\right\rfloor,
$$

where $J$ is the coefficient of the contact area, $q$ is the stress on the contact surface of the forwarder with the_soil, $a$ is the stress attenuation constant by the depth of the soil, and $b$ is the average width of the contact area approximately equal to the width of the wheel.

Compression of elementary soil layer with thickness of the elemental layer in deformable state $d z$ is determined by Eq. [28]:

$$
d h_{0}=\sigma /(E-\sigma) d z
$$

Then the total compression strain of the soil array is determined after integration ratio (17) and considering Eq. (16) and accepting that $E \gg>$ :

$$
\begin{aligned}
& h_{0}=\int_{0}^{H-h_{0}} \sigma / E d z \\
& =\frac{J q a b}{E} \arctan \left(\frac{H-h_{0}}{a b}\right)
\end{aligned}
$$


The disproportionate increase in compression strain with the acting stress approaching the bearing capacity of the soil is considered by coefficient $k_{S}$. At that, the actual value of subsidence $h$ is determined by the formula [28]:

$$
h=h_{0} k_{S}=h_{0} q_{s} /\left(q_{s}-q\right)
$$

where $q_{S}$ is the bearing capacity of the soil.

From Eqs. (18) and (19) follows:

$h=\frac{J q a b k_{S}}{E} \arctan \left(\frac{H-h / k_{S}}{a b}\right)=\frac{J q a b q_{S}}{E \cdot\left(q_{S}-q\right)} \arctan \left(\frac{H-h \cdot\left(q_{S}-q\right) / q_{S}}{a b}\right)(20)$

Equation (20) has no analytical solution concerning subsidence value $h$, thus, further calculations were made based on numerical methods. A special program has been compiled to implement the calculations. The values $J$ and $a$ included in equation (20) are determined by known formulas [28]:

$$
J=\frac{0.03+l / b}{0.6+0.43 l / b}
$$

where $l$ is the average length of the forwarder's contact area with the soil surface.

$$
\begin{aligned}
a & =1 /[0.64 \cdot b \cdot(1+b / H)] \\
q & =G_{W} / F
\end{aligned}
$$

where $G_{W}$ is the load on one wheel of the machine and $F$ is the contact area of the wheel and the soil surface.

The shape of the contact area of the wheeled forwarder and the soil varies from elliptical for solid soil to rectangular-like for soft soil (Figure 1).

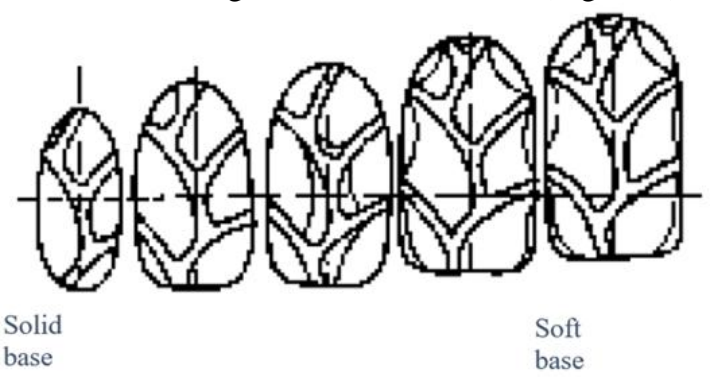

Fig. 1. Typical rollmarks of wheeled forwarder on different soils [35].

The area of an ellipse is defined by multiplying the lengths of axes by $0,25 \pi$ and the area of a rectangle is calculated by multiplying the lengths of sides. If the average width $b$ and the average length $l$ of the contact area is taken as the ellipse axis when operating on solid soils ( $E=3 \mathrm{MPa}$ according to the accepted classification) and as side lengths when operating on solid soils $(E=0.4 \mathrm{MPa}$ according to the accepted classification), the contact area can be generally expressed as follows:

$$
F=k_{F} b l \text {, }
$$

where $k_{F}$ is a coefficient of a form that depends on the soil condition.

Assuming an exponential deviation of the form coefficient from the soil deformation module, the form coefficient $k_{F}$ is defined as follows:

$$
k_{F}=0.8766 E^{0.1199}
$$

Formula (25) is illustrated as a graph in Fig. 2.

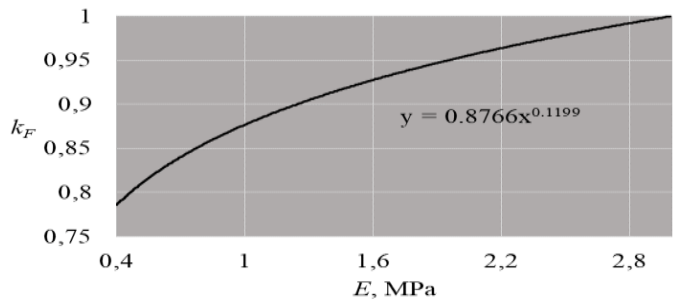

Fig. 2. The coefficient of contact area shape versus soil deformation module

Using Eqs. (24) and the ratio (25), the contact area can be defined as follows:

$$
F=0.8766 E^{0.1199} \mathrm{bl}
$$

The length of the contact area is calculated by a known ratio [28]:

$$
l=2 \sqrt{d \cdot h_{z}-h_{z}^{2}}+\sqrt{d \cdot\left(h_{z}+h\right)-\left(h_{z}-h\right)^{2}}
$$

where $d$ is the wheel diameter, $h_{Z}$ is axial deformation of the wheel.

The value of deformation $h_{Z}$ depends on the tire modification, the inner pressure in tire tube $p_{W}$, the load on the wheel $G_{W}$, and soil deformation. Several simple ratios are offered for determining the value $h_{Z}$, which allow reaching high accuracy in practical calculations. One of the most common ratios is called the Heidekel formula. It can be expressed as follows:

$$
h_{z}=G_{W} /\left(\pi p_{W} d\right)
$$

It should be noted that the bearing capacity value $q_{S}$ used in the Eq. (20) is not constant for the soil value [30]. It varies depending on geometrical parameters of a contact area and depth of press tool immersion. The bearing capacity of the soil can be determined by the following formula [30]:

$$
q_{s}=q_{s 0} \alpha_{z}
$$

where $q_{S 0}$ is the bearing capacity of the soil layer with unlimited thickness and $\alpha_{Z}$ is the thickness coefficient of the compressible soil layer.

At that, the bearing capacity value of the soil with unlimited thickness $q_{S O}$ is defined as [29]:

$$
\begin{aligned}
& q_{S 0} \\
& =0.5 J_{1} N_{1} \gamma b \\
& +N_{2} \gamma h \\
& +J_{2} N_{3} C_{0}
\end{aligned}
$$

where $N_{1}, \quad N_{2}, \quad N_{3}$, and $S$ are auxiliary coefficients, $J_{I}$ and $J_{2}$ are geometrical parameters of the press tool, which can be calculated as [30]:

$$
\begin{gathered}
J_{1}=l /(l+0.4 b) \\
J_{2}=(l+b) /(l+0.5 b)
\end{gathered}
$$

where $l$ is the length of the press tool and $b$ is the width.

The coefficients $N_{1}, N_{2}, N_{3}$, and $S$ can be calculated as follows [36]:

$$
\begin{gathered}
N_{1}=\left(1-S^{4}\right) / S^{5} \\
N_{2}=1 / S^{2} \\
N_{3}=2\left(1+S^{2}\right) / S^{3} \\
S=\tan \left(0.25 \pi-0.5 \phi_{0}\right)
\end{gathered}
$$


The thickness of deformable layer of the soil is calculated by the formula:

$$
\begin{aligned}
& \alpha_{Z} \\
& =1 \\
& +0.5 h H^{*} /\left[H \cdot\left(H-h-0.25 H^{*}\right)\right]
\end{aligned}
$$

where $H^{*}$ and $\varepsilon$ are auxiliary values and are determined in the formula [29]:

$$
\begin{aligned}
& H^{*} \\
& =0.707 b \tan \phi_{0} \cos \varepsilon \exp [(0.25 \pi \\
& +\varepsilon) \tan \varepsilon] \\
& \qquad \varepsilon=0.75 \phi_{0}
\end{aligned}
$$

From the analysis of dependencies (20)-(38) follows that based on Eqs. (8)-(13), which determine physical and mechanical properties of the soil depending on the deformation module $E$, and at known values of internal pressure in the tire tube $p_{W}$, wheel width $b$, wheel diameter $d$, and wheel load $G_{W}$, the equation (13) contains only one unknown value $h$. Subsidence value $\mathrm{h}$ is thus determined by the numerical solution of Eq. (13) at given values $E, p_{W}, b, d$, and $G_{W}$ and vice versa, from the given value $h$ it is also possible to calculate the corresponding value $G_{W}$.

The resistance force of the soil to deformation, i.e., the force of soil to withstand the rolling of the wheel, is determined by the formula [36]:

$$
F_{\mathrm{C}, \Gamma}=\int_{0}^{h} q d h=\int_{0}^{h} \frac{G_{W}}{F} d h
$$

Recurrence of the applied load is important to consider by studying the interaction of wheeled forwarders with the soil in the logging sites. Taking into account the number of axes of wheel forwarders, there are 3-4 consecutive passes of the wheel with a short time interval over one track by one machine passage.

The following empirical formula [32] was used to determine the recurrence of applied load:

$$
h=h_{(1)} n^{1 / a},
$$

where $h_{(1)}$ is the track depth after the passage of first axis wheels, $n$ is the number of forwarder's axes, and $a$ is an empirical coefficient that depends on properties and condition of the soil.

General experimental observations [37] are presented in Table 3.

Table 3. Values variation of the recurrence applied load [37].

\begin{tabular}{|r|r|}
\hline Soil & Coefficient $a$ \\
\hline Soft & $2 \ldots 3$ \\
\hline Normal & $3 \ldots 4$ \\
\hline Solid & $4 \ldots 5$ \\
\hline
\end{tabular}

When associating the deformation module values for different soil categories in with the soil quality characteristics based on Table 3, the dependence of the average coefficient $a$ on the deformation module $E$ can be presented in the form of a graph (Figure 3).

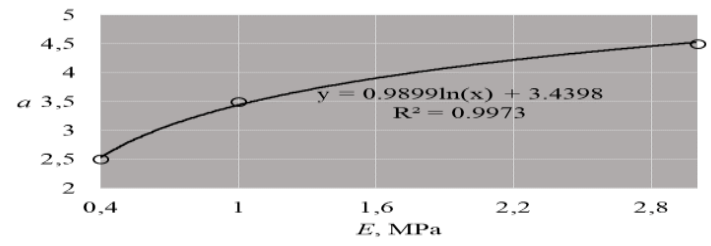

Fig. 3. Recurrence coefficient of applied load versus soil deformation module

The dependencies shown graphically in Fig. 3 are approximated with satisfactory accuracy by the following expression:

$$
a=0.9899 \ln E+3.4398 \text {. }
$$

The total resistance force of the machine's passage will be determined as follows. First, by solving the equation (20), the depth of the track should be calculated that corresponds to the given load on the wheel $G_{W}$. The track depth corresponding to the pass of the machine is determined by the formula (70) using the resulting value $h_{(1)}$. Afterward, the ratio $q=G_{W} / F$ within the variability of track depth from 0 to $h$ is defined based on (69), which integration by any numerical method gives the required value of the traction resistance force of the machine.

\subsection{Determination of the forwarder's adhesion to the soil surface}

Besides soil resistance to deformation, the adhesion of the wheeled forwarder to the surface of traction is one more important factor affecting the performance capacity of the forwarder.

The adhesion sufficient for movement without slipping is provided if following ratios are fulfilled (diagrams of restrictions are presented on Fig. 4) [28]:

$$
\begin{aligned}
& R_{A D 1}=G_{W} k_{\mathrm{H}} \phi_{\mathrm{P}}+F \\
& \cdot\left(1-k_{\mathrm{H}}\right) \\
& \cdot\left(q \tan \phi_{0}\right. \\
&\left.+C_{0}\right)>F_{R} \\
& R_{A D 2}=\sqrt{Q_{S}^{2}-G_{W}^{2}}>F_{R}
\end{aligned}
$$

where $k_{S}$ is the saturation coefficient of a tirethread, $\varphi_{P}$ is the friction coefficient of the wheels on the soil, and $Q_{S}$ is the allowable load on the soil limited by its bearing capacity.
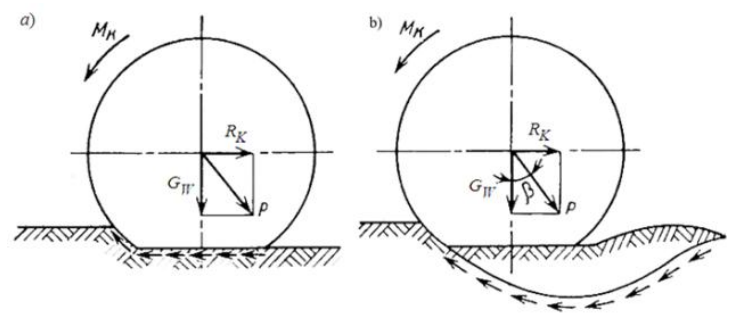

Fig. 4. Schemes of the wheel's adhesion limits to the soil [28]: a) the adhesion is limited by the resistance of the wheel to slide on the soil in the contact area (condition by formula (42)); $b$ ) the adhesion is limited by the bearing capacity of the soil (condition by formula (43)) 
The allowable load $Q_{S}$ is determined by the formula [33],[34]:

$$
Q_{s}=q_{s \beta} F \cos \beta,
$$

where $q_{S \beta}$ is the bearing capacity of the soil considering the deviation of the resulting load vector from the movement surface normal, $\beta$ is the angle of the resulting load application versus the movement surface normal.

Considering the deviation of the load vector from the normal, the bearing capacity is determined as follows $[28,29]$ :

$$
\begin{aligned}
q_{S \beta}=q_{S \beta 0} \alpha_{Z}= & \left(0.5 J_{1} N_{1} \gamma b K_{1}\right. \\
& +N_{2} \gamma h \\
& \left.+J_{2} N_{3} C_{0} K_{3}\right) \\
& \cdot \alpha_{Z},
\end{aligned}
$$

Coefficients $K 1$ and $K 3$ in the formula (45) are determined by dependencies [28]:

$$
\begin{aligned}
& K_{1}=\left(\pi-4 \beta \tan \varphi_{0}\right) /\left(\pi+4 \beta \tan \varphi_{0}\right), \\
& K_{3}=(3 \pi-2 \beta) /(3 \pi+2 \beta),
\end{aligned}
$$

The other values in (45) are calculated using Eqs. (31)-(38).

The application angle of the resulting load $\beta$ is determined based on the value of normal load $G_{W}$ and tangential reaction of the soil $R_{T}$ :

$$
\beta=\arctan \frac{R_{K}}{G_{W}}
$$

Thus, the tangential reaction of $R_{T}$ must therefore be determined in order to estimate the adhesion of the forwarder to the soil. This can be fulfilled using the scheme shown in Figure 5.

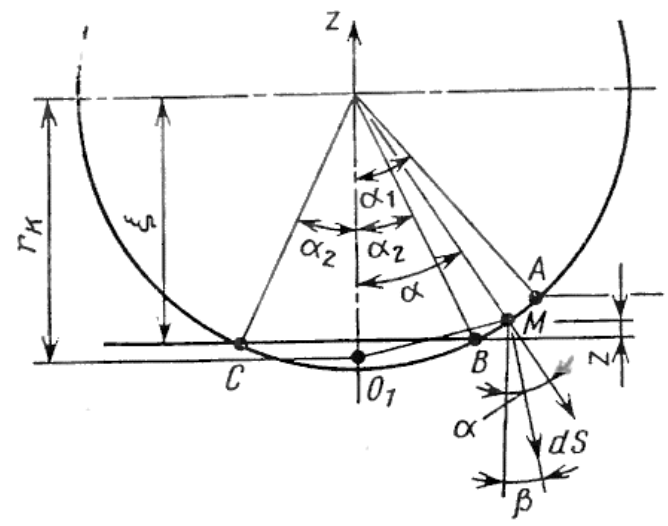

Fig. 5. Calculation scheme for determining the wheel's adhesion force to the soil [28].

When the wheel turns relatively to the instantaneous center $O_{l}$ by the angle $d \alpha$, the point $M$ is moving by the distance $d s=O_{1} M d \alpha$. The tangential component $d j$ of this movement is determined as follows:

$$
\begin{gathered}
d j=\sin (\alpha-\beta) d s=O_{1} M \sin (\alpha-\beta) d \alpha \\
\text { Distance } O_{1} M \text { is estimated by equations: } \\
O_{1} M=(\xi-z) \tan \alpha / \cos \beta_{K} \\
\beta_{K}= \\
\arctan \left\{\left[r_{R}-(\xi-z)\right] /(\xi-z) \tan \alpha\right\},
\end{gathered}
$$

where $r_{R}$ is the rolling radius of the wheel:

$$
r_{R}=r \cdot(1-\delta),
$$

where $r$ is the wheel radius, $\delta$ is the coefficient of slipping.

Therefore

$$
\begin{array}{r}
d j=\left[(\xi-z) / \cos \alpha-r_{K} \cos \alpha\right] d \alpha \\
j=\int_{\alpha_{1}}^{\alpha_{2}}\left[(\xi-z) / \cos \alpha-r_{K} \cos \alpha\right](-d \alpha)
\end{array}
$$

On the site $A B$ :

$$
\begin{aligned}
&(\xi-z) / \cos \alpha=r \\
& j_{1}=r \cdot\left(\alpha_{1}-\alpha\right)-r \cdot(1-\delta) \cdot\left(\sin \alpha_{1}-\sin \alpha\right)
\end{aligned}
$$

On the site $B C$ :

$$
\begin{aligned}
j_{2} & =r \cdot\left(\alpha_{1}-\alpha_{2}\right)-r \cdot(1-\delta) \cdot\left(\sin \alpha_{1}-\sin \alpha_{2}\right)+ \\
& +(\xi+h) \cdot \ln \frac{\tan \left(0,25 \pi+0,5 \alpha_{2}\right)}{\tan (0,25 \pi+0,5 \alpha)}
\end{aligned}
$$

The values of angles $\alpha_{1}$ and $\alpha_{2}$ are determined using the scheme in Figure 6 by the following equations [28]:

$$
\begin{gathered}
\alpha_{1}=\arccos \left[1-\left(h_{Z}+h\right) / r\right] \\
\alpha_{2}=\arccos \left[1-h_{Z} / r\right]
\end{gathered}
$$

The direct tangential force $R_{T}$ is determined by integrating the dependence of the shear stress $\tau$ on the shear strain $j_{1}$ and $j_{2}$ on the sites by any numerical method:

$$
\begin{aligned}
& R_{T} \\
& =b \cdot r \\
& \cdot\left(\int_{-\alpha_{2}}^{\alpha_{2}} \tau\left(j_{2}\right) d \alpha\right. \\
& \left.+\int_{\alpha_{2}}^{\alpha_{1}} \tau\left(j_{1}\right) d \alpha\right)
\end{aligned}
$$

The actual shear strain is determined considering its increase when the shear stress $\tau$ approaches the limit of the soil shear strength $\tau_{S H}$ by the formula [28]:

$$
j=j_{0} \tau_{S H} /\left(\tau_{S H}-\tau\right),
$$

where $j_{0}$ is the shear strain without taking into account its possible increase by the shear stress approaching the limit of the soil shear strength.

The soil deformation $j_{0}$ enclosed between the wheel lugs is related to the shear stress as follows:

$$
j_{0}=\tau \cdot t_{W L} / E_{1} \text {, }
$$

where $t_{W L}$ is the distance between the wheel lugs.

Substituting the (60) into the formula (59) results in:

$$
j=\tau \cdot t_{W L} \tau_{S H} /\left[\left(\tau_{S H}-\tau\right) \cdot E_{1}\right]
$$

The limit of the soil shear strength can be calculated as follows:

$$
\begin{aligned}
& \tau_{\mathrm{CP}}=q \tan \phi_{0}+ C_{0} \\
& \cdot\left(1-j / t_{\Gamma}\right)
\end{aligned}
$$


By substitution of Eq. (62) into the formula (61) and transformations in relation to $\tau$, the following ratio $\tau(j)$ can be defined:

$$
\tau=\frac{j E_{1} \cdot\left[t_{\Gamma} q \tan \varphi_{0}+C_{0} \cdot\left(t_{r}-j\right)\right]}{t_{\Gamma}\left[t_{\Gamma} q \tan \varphi_{0}+j E_{1}+C_{0} \cdot\left(t_{\Gamma}-j\right)\right]}
$$

The ratio (63) for three soil categories is graphically depicted in Figure $6(t g=0.14 \mathrm{~m}, q=$ $50 \mathrm{kPa}$ ).

The ratio (63) is substituted into formula (58). At that, the shear strain $j=j_{1}, j_{2}$ is determined by formulas (54), (55), and the integration limits $\alpha_{1}$ and $\alpha_{2}$ are determined by formulas (56), (57).

After calculating the tangential reaction $R_{T}$ by formula (58), it is possible to determine the angle of the resulting load application $\beta$. Thus, the solution of condition whether the forwarder's adhesion to the soil surface is fulfilled can be checked according to formulas (42) and (43).

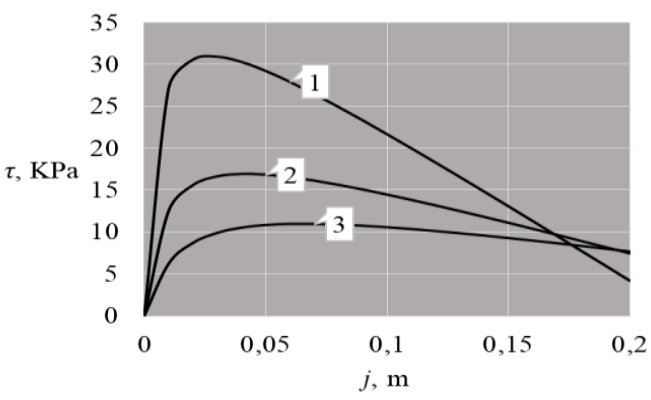

Fig. 6. Shear stress against soil shear strain values:

1) $E=3 \mathrm{MPa}, 2) E=1 \mathrm{MPa}, 3) E=0.4 \mathrm{MPa}$

Another important indicator is the propulsive coefficient, which in turn is determined by Eq. [28]:

$$
\phi_{P}=\frac{F_{A D}-F_{R}}{G_{\mathrm{K}}},
$$

This equation allows estimating the height of the threshold unevenness (i.e., the maximum height of the unevenness, which the wheels of the machine can overcome), by the following formula [28]:

$$
h_{u . t .}=R \cdot\left(1-\frac{1}{\sqrt{1+\phi_{P}^{2}}}\right),
$$

where $R$ is the wheel radius, $\varphi_{P}$ is the propulsive coefficient.

The last two equations form another limit on the volume of a skidded bunch of wood.

The data [33] convincingly show that there are certain links between the technical characteristics of modern wheeled forwarders John Deere, Rottne, Ponsse, Komatsu and Amkador. Based on default modifications the following approximate equations can be noted:

- for eight-wheeled forwarders:

$$
\begin{gathered}
{[M]=3.6124 \exp (0.0739 M),} \\
N=8.7318 M \\
N=17.194[M]^{0.8315}, \\
T=20.719[M]^{0.8157},
\end{gathered}
$$

- for six-wheeled forwarders:

$$
\begin{aligned}
& {[M]=2.5939 \exp (0.1009 M)} \\
& N=9.4329 M,
\end{aligned}
$$

$$
\begin{aligned}
& N=10.772[M]^{1.0012}, \\
& T=28.012[M]^{0.7032},
\end{aligned}
$$

The satisfactory value of determination coefficients $R^{2}$ in Eqs. (66)-(73) and obtained approximate ratios are suitable for further calculations of forwarders' productivity.

The performance capacity of the forwarders was estimated for the following soil categories:

- Category I - sand, sand loam, light (wet) loam, soil of plant layer, peat;

- Category II - - loam, small and medium gravel, light and clay;

- Category III - clay medium or heavy, loosened, dense loam

\section{RESULTS AND DISCUSSION}

\subsection{Assessment of the forwarder's productivity}

The influence of soil conditions on the forwarder's productivity was examined based on $8 \times 8$ vehicles used Eq.(1)-(7), with the following initial data [19,31,32]: $\varphi_{1}=0.8 ; T_{C M}=7 \mathrm{~h}, T_{M L}=$ $90 \mathrm{~s}, T_{R T}=30 \mathrm{~s}, t_{D Z U}=200 \mathrm{~s}, Q=1.5 \mathrm{~m} 3, \rho=850$ $\mathrm{kg} / \mathrm{m} 3, \eta=0.8$. The values of $\varphi_{R}$. were taken from Tables 1 and 2. The weight of the machine, the engine capacity by the equation, and the maximum tractive force are determined based on the analysis data [33]. The volume of skidded timber logs is limited only by the load-carrying capacity of the vehicle.

Figure 7 depicts the ratio of maximum traction force $T$ versus forwarder's traction resistance $F_{S}$ depending on the traction resistance coefficient $\varphi_{R}$. At that, by varying the coefficient within 0.1-0.5, the value $F_{R}$ does not exceed the maximum traction force. Thus, limiting the volume of skidded timber to the maximum traction force is a matter of low importance for modern wheeled vehicles.

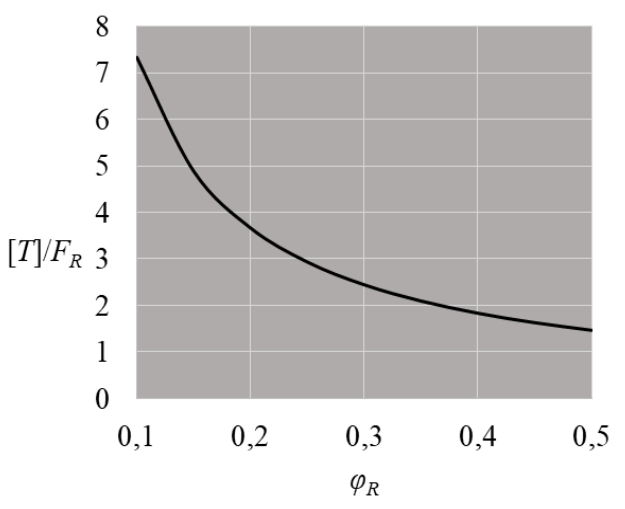

Fig. 7. Maximum traction force $T$ versus forwarder's traction resistance force $F_{R}$

As a first approximation, the adhesion coefficient $\varphi_{A D}$ changes linearly depending on the traction resistance coefficient $\varphi_{R}$. At that, the value $\varphi_{A D}=0.6$ and $\varphi_{A D}=0.3$ correspond to $\varphi_{R}=0.1$ and $\varphi_{R}=0.4$, respectively. In this case, the adhesion force $F_{A D}$ versus the traction force $F_{R}$ can be presented as a diagram in Figure 8. It depicts that a limit on the weight of loaded forest machinery is 
applicable to operation on relatively soft soil. Current knowledge on how the adhesion coefficient changes depending on soil condition is not sufficient and requires additional studies in this sphere.

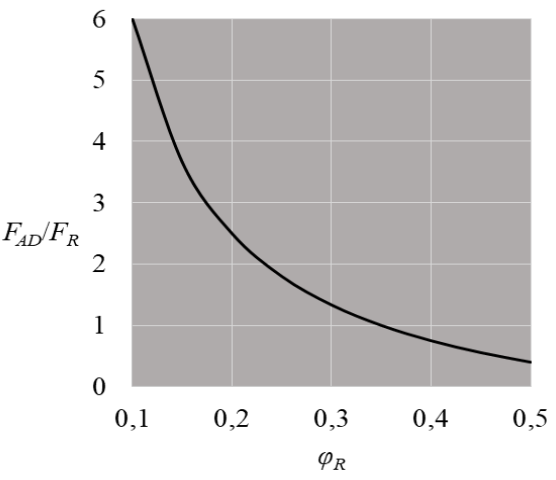

Fig. 8. Adhesion force $F_{A D}$ versus traction resistance force $F_{R}$

Diagrams of changes of the loaded forwarder's speed $U_{L}$ depending on the maximum load-carrying capacity of the machine $[M]$ and the traction resistance coefficient $\varphi_{R}$ are presented in Figure 9. It can be seen that the traction resistance force significantly influences the speed of the vehicle. At the same volume of skidded timber, the traction speed of the machine varies by 4-5 times depending on the skidding conditions. Thus, the necessity to examine the interaction between grapple skidders and the soil of logging sites remains of great interest.

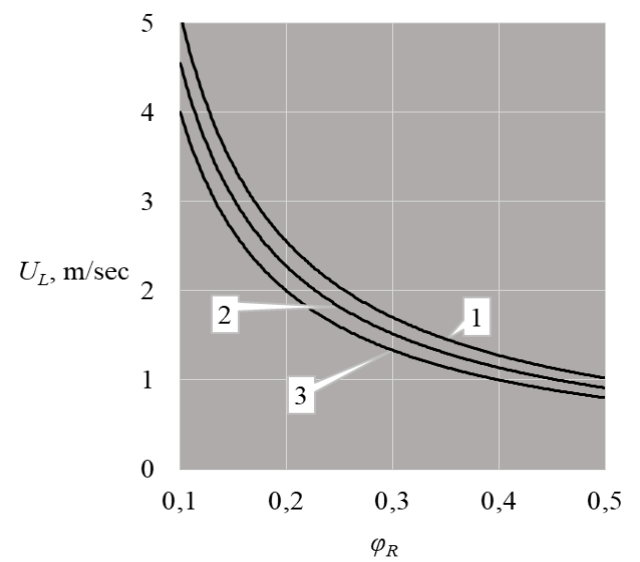

Fig. 9. Variation of the loaded forwarder's speed $U_{L}$ depending on the maximum load-carrying capacity $[M]$ and the traction resistance coefficient $\left.\varphi_{R} 1\right)[M]=20$ tons; 2 ) $[M]=15$ tons; 3 ) $[\mathrm{M}]=10$ tons.

The last statement is supported by diagrams in Figure 10, which shows the share of traction time $T_{T}$ (movement time of the loaded vehicle versus that of the unloaded) in total duration of the skidding cycle $T_{C}$ depending on the average skidding distance $l_{A V}$ at forwarder's load-carrying capacity of 10 tons.

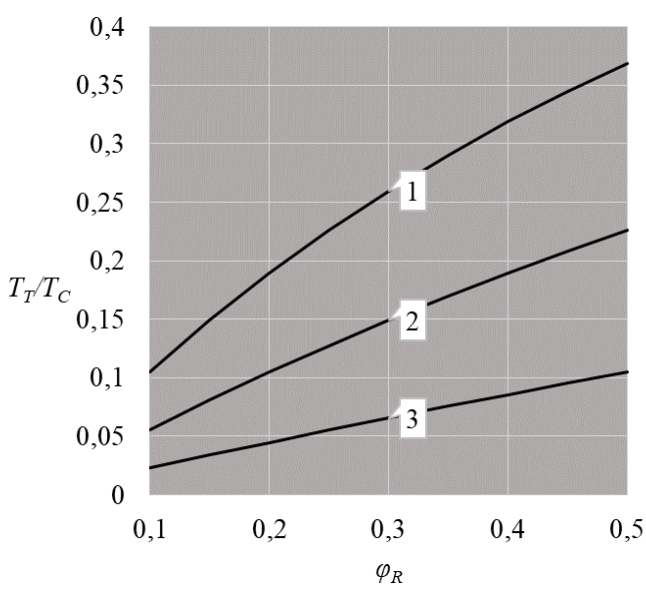

Fig. 10. Share of traction time in total duration of skidding cycle depending on the average skidding distance: $\left.\left.l_{A V}=500 \mathrm{~m}, 2\right) l_{A V}=250 \mathrm{~m}, 3\right) l_{A V}=100 \mathrm{~m} ; \mathrm{Tt}-$ traction; Tc - cycle

Figures 11 and 12 show the effect of the traction resistance coefficient on the output of the forwarder per shift at different average skidding distances for a vehicle with a load capacity of 10 and 20 tones, respectively. Figure 13 depicts the dependence of the forwarder's output per shift on the traction resistance coefficient with varying the load capacity values at different average skidding distances $l_{A V}$.

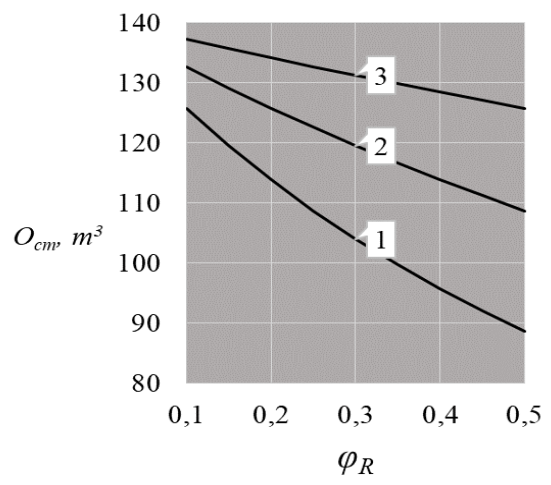

Fig. 11. Influence of traction resistance coefficient on forwarder's output per shift $([M]=10 \mathrm{t}): 1) l_{A V}=500 \mathrm{~m}$; 2) $l_{A V}=250 \mathrm{~m}$; 3) $l_{A V}=100 \mathrm{~m}$.

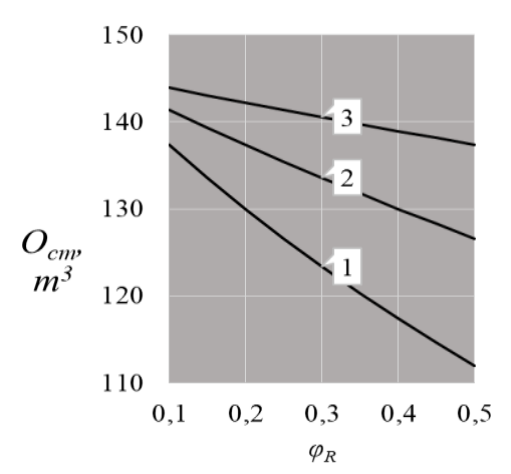

Fig. 12. Influence of traction resistance coefficient on forwarder's output per shift $([M]=20 \mathrm{t}):$ 1) $l_{A V}=500 \mathrm{~m}$; 2) $\left.l_{A V}=250 \mathrm{~m} ; 3\right) l_{A V}=100 \mathrm{~m}$. 

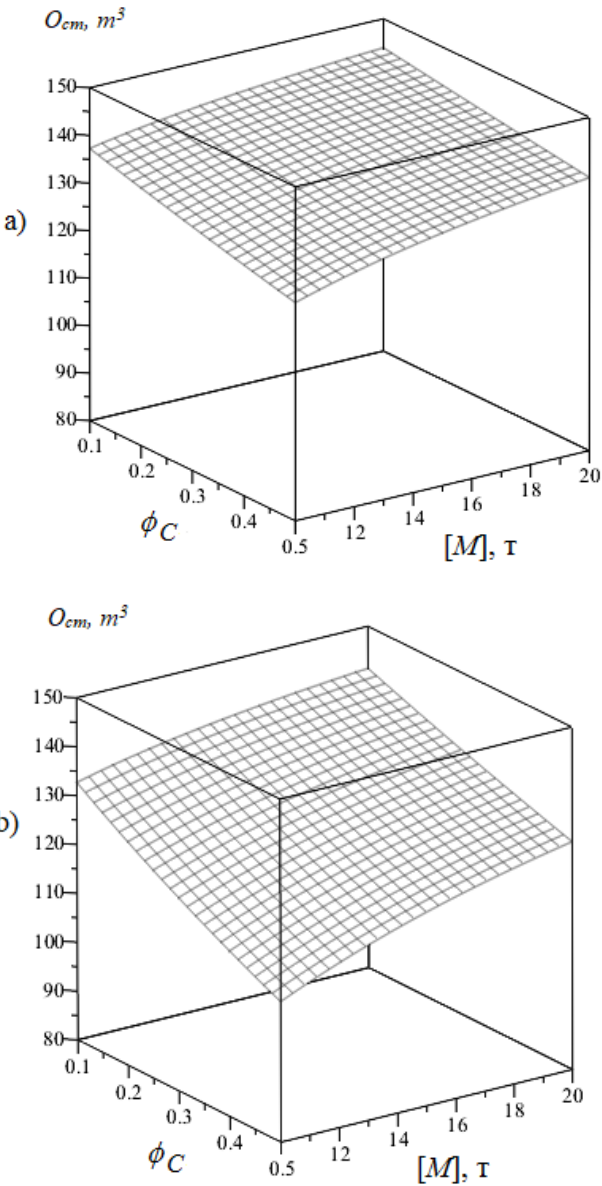

c)

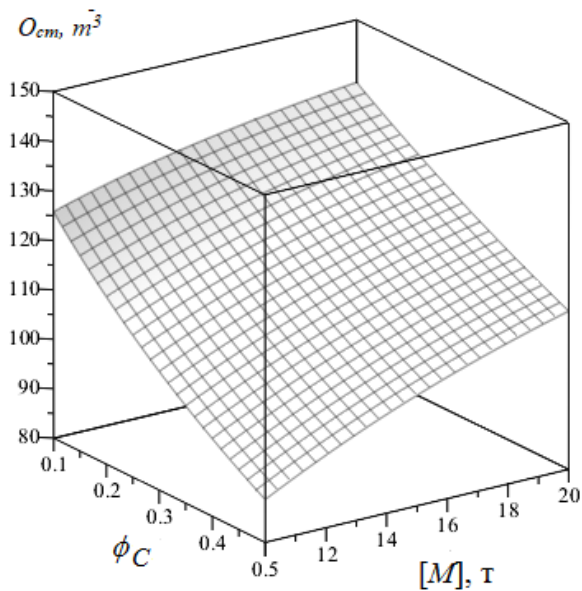

Fig. 13. The output of the forwarder per shift versus the traction resistance coefficient at different load capacity values: a) $l_{A V}=100 \mathrm{~m}$; b) $l_{A V}=250 \mathrm{~m}$; c) $l_{A V}=500 \mathrm{~m}$.

The analysis of charts in Figs. 11-13 shows a noticeable effect of the forwarder's traction coefficient on its output per shift. This effect is more visible by forwarders with low carrying capacity, often used for skidding on relatively weak soils.

\subsection{Assessment of the forwarder's traction resistance force}

Calculation patterns for values $h$ versus $G_{W}$ based on Eq. (20) are shown in Figures 14-16 for different soil categories at various width of the wheel $b$.

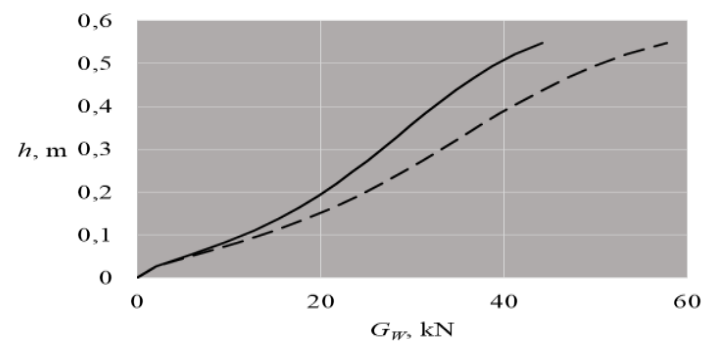

Fig. 14. Subsidence as a function of load on the wheel (solution of equation (49), soil with deformation module $E=0.4 \mathrm{MPa}$, continuous line $-b=0.7 \mathrm{~m}$, and dotted line $-b=0.8 \mathrm{~m})$

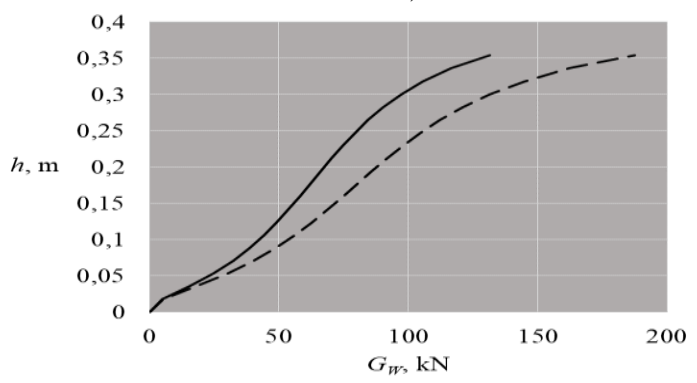

Fig. 15. Subsidence versus the load on the wheel (Eq.

(49), the soil with deformation module $E=1 \mathrm{MPa}$, continuous line $-b=0.7 \mathrm{~m}$, and dotted line $-b=0.8 \mathrm{~m}$ )

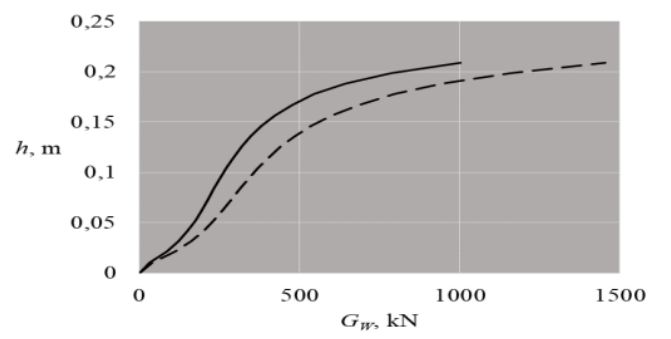

Fig. 16. Subsidence versus the load on the wheel (Eq. (49), the soil with deformation module $E=3 \mathrm{MPa}$, continuous line $-b=0.7 \mathrm{~m}$, and dotted line $-b=0.8 \mathrm{~m}$ )

The ratio of values $q$ versus $h$ is shown in Figures 17 and 18.

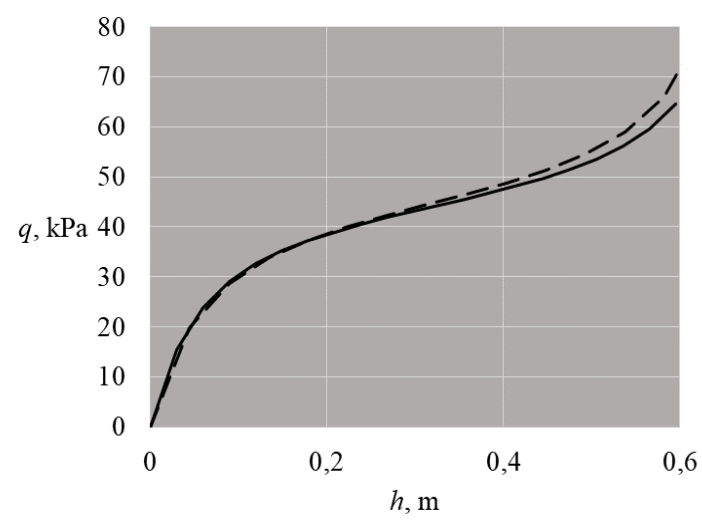

Fig. 17. Pressure in the contact area versus soil subsidence (the soil with deformation module $E=0.4$ $\mathrm{MPa}$, continuous line $-b=0.7 \mathrm{~m}$, and dotted line $-b=$ $0.8 \mathrm{~m})$ 


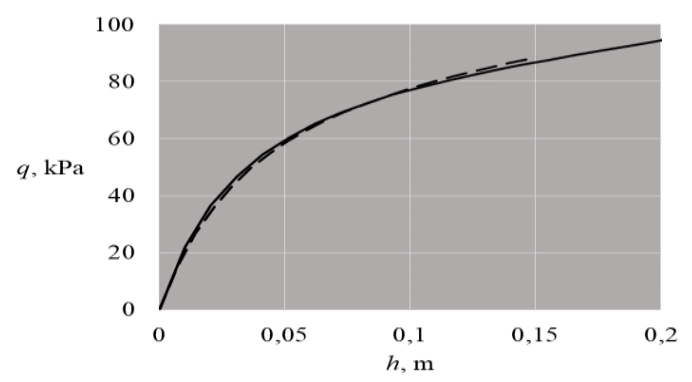

Fig. 18. Pressure in the contact area versus soil subsidence (the soil with deformation module $E=1 \mathrm{MPa}$, continuous line $-b=0.7 \mathrm{~m}$, and dotted line $-b=0.8 \mathrm{~m}$ )

For example, track depth after the passage of the first-axles-wheels will amount to $h_{(1)}=0.127 \mathrm{~m}$ employing a 4-axes-forwarder with a load capacity of $20 \mathrm{t}$ on the soil of II category with deformation module $E=1 \mathrm{MPa}$. The load on the wheel, in this case, is $50 \mathrm{kN}$ and $b=0.7 \mathrm{~m}$. Then, the total track depth after the forwarder's passage is $h=0.19 \mathrm{~m}$, according to (39). The resistance force is determined by integrating the $q(h)$ dependence (Fig. 18) within the $h$ limits from 0 to $0.19 \mathrm{~m}$ and multiplying the obtained value by the wheel width $b$ $=0.7 \mathrm{~m}$. The calculation value of the forwarder's resistance force to rolling will amount to $7.819 \mathrm{kN}$.

\subsection{Assessment of the forwarder's productivity with respect to soil conditions}

Input data for the calculation are presented in Table 4.

Table 4. Input data for calculating wheeled forwarders' skidding capacity depending on soil and ground

\begin{tabular}{|c|c|c|c|c|}
\hline $\begin{array}{r}\text { Paramet } \\
\text { er }\end{array}$ & $\begin{array}{r}\text { Unit } \\
\text { measureme } \\
\text { nts }\end{array}$ & $\begin{array}{l}\text { Minimu } \\
\text { m value }\end{array}$ & $\begin{array}{l}\text { Maximu } \\
\text { m value }\end{array}$ & $\begin{array}{r}\text { Variati } \\
\text { on } \\
\text { interval } \\
\end{array}$ \\
\hline $\begin{array}{r}\text { Number } \\
\text { of axes }\end{array}$ & - & 3 & 4 & 1 \\
\hline $\begin{array}{l}\text { Maximu } \\
\text { m load- } \\
\text { carrying } \\
\text { capacity }\end{array}$ & ton & 10 & 20 & 5 \\
\hline $\begin{array}{r}\text { Cargo } \\
\text { weight } \\
\text { vs. } \\
\text { maximu } \\
\text { m load- } \\
\text { carrying } \\
\text { capacity }\end{array}$ & - & 0,5 & 1 & 0.75 \\
\hline $\begin{array}{r}\text { Tire } \\
\text { width }\end{array}$ & $\mathrm{m}$ & 0.7 & 0.8 & 0.1 \\
\hline
\end{tabular}

Calculations were made for soils of I, II, III categories. Engine power $N$, maximum propulsive effort $T$, and the weight of the forwarder $\mathrm{M}$ were estimated concerning the maximum load-carrying capacity $[M]$ by formulas (66)-(69) for 4-axle forwarders and by (70)-(73) for 3-axle forwarders. The wood density was assumed to be $0.85 \mathrm{t} / \mathrm{m} 3$. Load on the wheel was determined by dividing the total weight of the loaded forwarder by the number of wheels. The movement speed and speed of unloaded forwarder were calculated by formulas (4), (5). The output capacity was determined by Eq. (1).

When implementing the model, the physical and mechanical properties of the soil were expressed through the deformation module by expressions (8)(11), (14). The basic equation of track depth and pressure relation is represented by formula (20), in which auxiliary coefficients are defined by formulas (21) and (22), pressure and contact area are defined by formulas (23), (26)-(28), and bearing capacity of the soil is estimated by formulas (29)(38).

The rolling resistance force of the wheel caused by the soil resistance is calculated by the formula (39). The impact of transfer number (i.e., the number of forwarder's axles) on process indicators is estimated by formulas (40) and (41). The propulsor's adhesion force to the soil is determined according to (47) by the allowable load on the soil limited by its bearing capacity with (44)-(46), (53)(58), and (63). The height of the threshold unevenness, which the machine can overcome, is calculated by formulas (64) and (65). An example of the model implementation results is presented in Table 5.

Table 5. Calculations of skidding process parameters (for soils of III category, 3-axle forwarder with tire width

\begin{tabular}{|r|r|r|r|r|r|r|}
\hline $\begin{array}{r}{[M], \mathrm{t}} \\
K_{L}, \%\end{array}$ & 10 & 10 & 10 & 15 & 15 & 20 \\
\cline { 2 - 7 } & 50 & 75 & 100 & 50 & 75 & 50 \\
\hline$\varphi_{\mathrm{T}}$ & 0.09 & -0.13 & -0.33 & -0.09 & -0.39 & -0.36 \\
\hline$\varphi_{R}$ & 0.28 & 0.43 & 0.52 & 0.41 & 0.57 & 0.57 \\
\hline$\varphi_{A D}$ & 0.37 & 0.29 & 0.19 & 0.32 & 0.18 & 0.21 \\
\hline$\left[h_{\Pi}\right], \mathrm{m}$ & 0.01 & - & - & - & - & - \\
\hline$Q, \mathrm{~m}^{3}$ & 5.9 & 8.8 & 11.8 & 8.8 & 13.2 & 11.8 \\
\hline$G_{W}, \mathrm{kN}$ & 62.39 & 70.56 & 54.21 & 38.88 & 30.7 & 56.02 \\
\hline$U_{\mathrm{T}}, \mathrm{m} / \mathrm{sec}$ & 1.82 & - & - & - & - & - \\
\hline$U_{U}, \mathrm{~m} / \mathrm{sec}$ & 2.47 & - & - & - & - & - \\
\hline$h_{(1)}, \mathrm{m}$ & 0.19 & 0.34 & 0.5 & 0.32 & 0.53 & 0.45 \\
\hline$h_{(10)}, \mathrm{m}$ & 0.47 & 0.85 & 1.23 & 0.8 & 1.31 & 1.11 \\
\hline$h_{(50)}, \mathrm{m}$ & 0.88 & 1.61 & 2.32 & 1.52 & 2.48 & 2.09 \\
\hline$O_{(100)}, \mathrm{m}^{3}$ & 108 & - & - & - & - & - \\
\hline$O_{(250)}, \mathrm{m}^{3}$ & 86 & - & - & - & - & - \\
\hline$O_{(500)}, \mathrm{m}^{3}$ & 64 & - & - & - & - & - \\
\hline
\end{tabular}

The results of the analysis are summarized in Tables 6 and 7. When working on the soils of the I and II category, the adhesion force of the forwarder 
with the surface is sufficient to move without slipping on all types of soils, i.e., soft, medium, and solid (Table 6). Lightweight 3-axle forwarders with normal tires width and at $50 \%$ body load, 4-axle forwarders with 50 and $75 \%$ body load, as well as medium-weight forwarders with $50 \%$ body load can operate without slipping on soils of category III. Lightweight 3-axle forwarders with 50 and $75 \%$ body load and medium forwarders with $50 \%$ body load as well as lightweight 4-axle forwarders with 50 and $75 \%$ body load, medium forwarders with $50 \%$ body load, and heavy forwarders with $50 \%$ body load are suitable for movement without slipping and at larger tire widths.

Table 6. Soil categories vs. maneuverability of forwarders under sufficient adhesion conditions with a surface

\begin{tabular}{|c|c|c|c|c|c|c|c|}
\hline & $n$ & \multicolumn{3}{|c|}{3} & \multicolumn{3}{|c|}{4} \\
\hline$b$ & $M$ & 50 & 75 & $\begin{array}{c}10 \\
0\end{array}$ & 50 & 75 & $\begin{array}{c}10 \\
0\end{array}$ \\
\hline \multirow{3}{*}{$\begin{array}{l}0 . \\
7\end{array}$} & 10 & $\begin{array}{c}\text { I,II,II } \\
\text { I }\end{array}$ & I,II & $\mathrm{I}, \mathrm{II}$ & $\begin{array}{c}\text { I,II,II } \\
\text { I }\end{array}$ & $\begin{array}{c}\mathrm{I}, \mathrm{II}, \mathrm{II} \\
\mathrm{I}\end{array}$ & I,II \\
\hline & 15 & I,II & I,II & $\mathrm{I}, \mathrm{II}$ & $\begin{array}{c}\text { I,II,II } \\
\text { I }\end{array}$ & $\mathrm{I}, \mathrm{II}$ & $\mathrm{I}, \mathrm{II}$ \\
\hline & 20 & I,II & I,II & I,II & I,II & I,II & I,II \\
\hline \multirow{3}{*}{$\begin{array}{c}0 . \\
8\end{array}$} & 10 & $\begin{array}{c}\mathrm{I}, \mathrm{II}, \mathrm{II} \\
\text { I }\end{array}$ & $\begin{array}{c}\mathrm{I}, \mathrm{II}, \mathrm{II} \\
\text { I }\end{array}$ & I,II & $\begin{array}{c}\mathrm{I}, \mathrm{II}, \mathrm{II} \\
\text { I }\end{array}$ & $\begin{array}{c}\mathrm{I}, \mathrm{II}, \mathrm{II} \\
\text { I }\end{array}$ & I,II \\
\hline & 15 & $\begin{array}{c}\mathrm{I}, \mathrm{II}, \mathrm{II} \\
\text { I }\end{array}$ & I,II & I,II & $\begin{array}{c}\mathrm{I}, \mathrm{II}, \mathrm{II} \\
\text { I }\end{array}$ & I,II & I,II \\
\hline & 20 & I,II & I,II & $\mathrm{I}, \mathrm{II}$ & $\begin{array}{c}\text { I,II,II } \\
\text { I }\end{array}$ & $\mathrm{I}, \mathrm{II}$ & I,II \\
\hline
\end{tabular}

Table 7. Soil categories with the track depth not more than $0.1 \mathrm{~m}$

\begin{tabular}{|c|c|c|c|c|c|c|c|}
\hline & $n$ & \multicolumn{3}{|c|}{3} & \multicolumn{3}{|c|}{4} \\
\hline \multirow{5}{*}{0} & $K_{L}$ & 50 & 75 & 100 & 50 & 75 & 100 \\
\hline \multirow{5}{*}{0.7} & 10 & I, II & I,II & I,II & I, II & I,II & I,II \\
\cline { 2 - 8 } & 15 & I, II & I,II & I & I, II & I,II & I,II \\
\cline { 2 - 8 } & 20 & I, II & I & I & I, II & I,II & I \\
\hline \multirow{5}{*}{0.8} & 10 & I, II & I,II & I,II & I, II & I,II & I,II \\
\cline { 2 - 8 } & 15 & I, II & I,II & I & I, II & I,II & I,II \\
\cline { 2 - 8 } & & I, II & I,II & I & I, II & I,II & I,II \\
\hline
\end{tabular}

The data in Table 7 shows that regardless of the weight of a forwarder and at full-body load, the track depth cannot exceed the value of more than $0.1 \mathrm{~m}$ when working on the soils of the I category. At the normal width of the tire, the depth of the track goes below $0,1 \mathrm{~m}$ while operating on soils of II category with 3-axle medium-weight forwarders with $100 \%$ body load and with heavy forwarders with more than $75 \%$ body load. By larger tire widths, medium and heavy 3-axle forwarders with
$100 \%$ body load leave a track of more than $0.1 \mathrm{~m}$, as well as do 4-axle heavy forwarders with normal tire width.

The propulsive coefficient can be calculated as follows $\left(\mathrm{R}^{2}=0.9504\right)$ :

$$
\begin{aligned}
& \phi_{P} \\
& =0,58-0.024 \\
& \cdot \frac{(0.01 K+0.53)(M+11)(0.99-B)}{E^{1.1}}
\end{aligned}
$$

Estimation of propulsive force is based on the formula (74), which allows assessing the maneuverability of the wheeled forwarder at sufficient adhesion with the soil and by varying the load-carrying capacity, body load factor, the width of the wheel, and deformation module of the soil. Together with Eq. (65), the formula (74) can be used to calculate the maximum height of the unevenness that a forwarder can overcome under given conditions.

An equation is also compiled to estimate the track depth after the first pass of the forwarder $\left(\mathrm{R}^{2}\right.$ $=0.9205)$ :

$$
\begin{aligned}
& h_{(1)} \\
& =0.0799 \\
& . \frac{(0.01 K-0.00616)(M+2,8)(0.01 B+0.0667)}{E^{1.68}}
\end{aligned}
$$

Formula (75) allows estimating the track depth after the first pass of the forwarder by varying the load capacity, body load coefficient, wheel width, and soil deformation module. At a given value of allowable track depth, the formula (75) can be used to set the forwarder's load factor based on its maximum load-carrying capacity, wheel width, and soil deformation module.

\subsection{Results and Discussion}

Currently, physical parameters of the soil are generally considered to be the most useful for assessing impacts on soil from vehicle movements [38]. For this reason, the bulk density, subsidence resistance, shear resistance, and soil porosity of soil were applied to measure soil compaction. According to previous studies $[39,40]$, the results of this research showed that the investigated physical soil parameters were significantly influenced mainly by the first passes of a vehicle. Similar results concerning the impact of the forwarder on the soil were recorded for the same wood extraction parameters in Italian Alps [41]. Other studies, however, report the opposite results. Gondard et al. [42] assessed the impact of logging in the Aleppo pine forests (Pinus halepensis) in southern France using both forwarders and skidders and reported deep soil disturbance, i.e., removal of topsoil and exposure of lower layers, according to proposed methods and classification [43] only when using a skidding tractor without track formation. Deconchat [44] has noted the same results for mixed oak groves (Quercus robur, Q. petraea and Q. pubescens) in southern France in an oceanic climate. This study focuses mainly on soil 
disturbance by skidders rather than forwarders, although skidders accounted for less than $1 \%$ of the skidding operations. However, both studies were performed based on methods developed to assess the disturbance of the soil surface by simply observing the condition of the soil after felling so that less noticeable effects such as soil compaction cannot be immediately detected.

Besides, the first research was carried out in dry soil conditions with high compaction resistance, where only scratching of timber logs can have any impact. The current study focuses, among others, on frozen soils of the high latitude of low density and high water content. Although obtained in this study results show the significant extent of soil disturbance by forwarders, there is more potential to soften negative consequences specifically for forwarders by optimizing their routes and load capacity and selecting more suitable modification of the forwarder for particular landscape and soil type.

\section{CONCLUSIONS}

Based on the obtained results, the following conclusions can be drawn. The comprised model of the interaction process between the wheeled forwarder and the soil is based on the physical theories considering the complex influence of soil and terrain conditions, the parameters of the wheeled propulsor, as well as load and cycles number of its application on the indicators of resistance and adhesion of the forwarder with the traction surface. The presented 75 equations in this model contain accounts of the physical processes of forest soil deformation, rut depth and wheel pressure, bearing capacity and strength of soil resistance, adhesion force, etc. The analysis of technical characteristics of modern wheeled forwarders John Deere, Rottne, Ponsse, Komatsu, and Amkador revealed that the links between the load capacity of machines and their weight, engine power and their weight, maximum propulsion force with load capacity are described for 4-axle and 3axle forwarders with the accuracy satisfactory for practical calculations. Testing results of the developed model, body load levels for 3- and 4-axle forwarders were defined depending on the type of the loading body, tire size, and soil category. The assessment of adhesion and traction and force without slipping was made. Besides, the depth of the wheel immersion at $100 \%$ loading for different types of bodies was estimated. Based on calculation results, the practice applicable equations were derived to estimate the traction coefficient of the rut depth after first passage depending on the values of load-bearing capacity, body loading coefficient, wheel width, and deformation module of soil. The approach chosen in this paper can serve as a basis for application in skidding roads projection, soil damage assessment, and another research in this field in future.

\section{REFERENCES}

1. Jamshidi R, Jaeger D, Raafatnia N, Tabari M. Influence of two ground-based skidding systems on soil compaction under different slope and gradient conditions. International journal of forest engineering, 2008; 19: 9-16.

2. Varol T, Emir T, Akgul M, Ozel HB, Acar HH, Cetin M. Impacts of Small-Scale Mechanized Logging Equipment on Soil Compaction in Forests. Journal of Soil Science and Plant Nutrition. 2020; 1: 1-11. https://doi.org/10.1007/s42729-020-00182-5

3. Cambi M, Hoshika Y, Mariotti B, Paoletti E, Picchio R, Venanzi R, Marchi E. Compaction by a forest machine affects soil quality and Quercus robur L. seedling performance in an experimental field. Forest Ecology and Management. 2017; 384: 406-414. https://doi.org/10.1016/j.foreco.2016.10.045

4. Uskov V, Bulat P, Arkhipova L. Classification of gasdynamic discontinuities and their interference problems. Research Journal of Applied Sciences, Engineering and Technology, 2014. 8(22): 2248-2254

5. Toivio J, Helmisaari HS, Palviainen M, Lindeman H, Ala-Ilomäki J, Sirén M, Uusitalo J. Impacts of timber forwarding on physical properties of forest soils in southern Finland. Forest ecology and management. 2017;405:22-30. https://doi.org/10.1016/j.foreco.2017.09.022

6. Cambi M, Certini G, Neri F, Marchi E. The impact of heavy traffic on forest soils: A review. Forest ecology and management. 2015; 338: 124-138.

https://doi.org/10.1016/j.foreco.2014.11.022

7. Parkhurst BM, Aust WM, Bolding MC, Barrett SM, Carter EA. Soil response to skidder trafficking and slash application. International journal of forest engineering. 2018; 29: 31-40.

https://doi.org/10.1080/14942119.2018.1413844

8. McFero Grace J, Skaggs RW, Cassel DK. Soil physical changes associated with forest harvesting operations on an organic soil. Soil Science Society of America Journal. 2006; 70: 503-509.

9. Han SK, Lee KC, Oh JH, Mun HS, Lee ST, Choi YS, Choi BK. Characteristics of Soil Disturbance Caused by Passages of Harvester and Forwarder in Cut-toLength Harvesting Operations. Journal of Korean Society of Forest Science. 2019; 108: 67-76. https://doi.org/10.14578/jkfs.2019.108.1.67

10. Lyakhov SV, Budalin SV. Development of Hardware and Software Complex for Increase of Technical Readiness Transport-Technological Machines in Forestry. In International Conference on Industrial Engineering (pp. 667-678). Springer, Cham; 2019. https://doi.org/10.1007/978-3-030-22063-1_71

11. Egorova TP, Delakhova AM. Improved system of adaptation of motor transport for operation in extremely low-temperature areas. In International Conference" Aviamechanical engineering and transport"(AVENT 2018). Atlantis Press; 2018. https://doi.org/10.2991/avent-18.2018.24

12. Bouchard M, D'Amours S, Rönnqvist M, Azouzi R, Gunn E. Integrated optimization of strategic and tactical planning decisions in forestry. European Journal of Operational Research. 2017; 259(3): 11321143. https://doi.org/10.1016/j.ejor.2016.11.022

13. Pulido-Moncada M, Munkholm LJ, Schjønning P. Wheel load, repeated wheeling, and traction effects on subsoil compaction in northern Europe. Soil and 
Tillage Research. 2019; 186: 300-309. https://doi.org/10.1016/j.still.2018.11.005

14. Walz J, Knoblauch C, Böhme L, Pfeiffer EM. Regulation of soil organic matter decomposition in permafrost-affected Siberian tundra soils-Impact of oxygen availability, freezing and thawing, temperature, and labile organic matter. Soil Biology and Biochemistry. 2017; 110: 34-43. https://doi.org/10.1016/j.soilbio.2017.03.001

15. Rudov SE, Shapiro VY, Grigor'eva OI, Grigor'ev IV, Kunitskaya OA. Features of Contact Interaction between the Skidding System and Frozen Soils. Lesnoy Zhurnal (Forestry Journal). 2019; 1: 106-119

16. Rudov SE, Grigorev IV, Kunitskaya OA, Druzyanova VP, Pekhutov AS, Ivanov AP, Ivanov AK, Okhlopkova MK, Pankov VYu, Borovikov RG. Specific features of accounting of state of the massive of the frozen soil grounds under cyclic loads. Bulgarian Journal of Agricultural Science. 2019; 25: 191-205.

17. Rudov SE, Voronova AM, Chemshikova JM, Teterevleva EV, Kruchinin IN, Dondokov YuZh, Khaldeeva MN, Burtseva IA, Danilov VV, Grigorev IV. Theoretical approaches to logging trail network planning: increasing efficiency of forest machines and reducing their negative impact on soil and terrain. Asian Journal of Water, Environment and Pollution. 2019; 16: 61-75. https://doi.org/10.3233/AJW190049

18. Rudov SE, Grigorev IV, Kunitskaya OA, Ivanov NA, Kremleva LV, Myuller OD, Gerts EF, Chemshikova YuM, Teterevleva EV, Knyazev AV. Method of variational calculation of influence of the propulsion plants of forestry machines upon the frozen and thawing soil grounds. International Journal of Advanced Science and Technology. 2019; 28: 179197.

19. Rudov S, Shapiro V, Grigorev I, Kunitskaya O, Druzyanova V, Kokieva G, Filatov A, Sleptsova M, Bondarenko A, Radnaed D. Specific features of influence of propulsion plants of the wheel-tyre tractors upon the cryomorphic soils, soils, and soil grounds. International Journal of Civil Engineering and Technology. 2019; 10: 2052-2071.

20. Grigorev MF, Grigoreva AI, Grigorev IV, Kunitskaya OA, Stepanova DI, Savvinova MS, Sidorov MN, Tomashevskaya EP, Burtseva IA, Zakharova OI. Experimental findings in forest soil mechanics. EurAsian Journal of BioSciences. 2018; 12: 277-287.

21. Ivanov VA, Grigorev IV, Gasparyan GD, Manukovsky AY, Zhuk AYu, Kunitskaya O.A., Grigoreva O.I. Environment-friendly logging in the context of water logged soil and knob-and-ridge terrain. Journal of Mechanical Engineering Research and Developments. 2018; 41: 22-27.

22. Manukovsky AY, Grigorev IV, Ivanov VA, Gasparyan GD, Lapshina ML, Makarova YuA, Chetverikova IV, Yakovlev KA, Afonichev DN, Kunitskaya OA. Increasing the logging road efficiency by reducing the intensity of rutting: mathematical modeling. Journal of Mechanical Engineering Research and Developments. 2018; 41: 35-41.

23. Bulat PV, Chernyshev MV. Existence regions of shock wave triple configurations. International Journal of Environmental and Science Education, 2016; 11(11): 4844-4854.

24. Frederick JM, Thomas MA, Bull DL, Jones CA, Roberts JD. The Arctic coastal erosion problem.
Sandia Nat. Lab., Albuquerque, NM, USA, Tech. Rep. SAND2016-9762; 2016.

25. Hitomi K. Manufacturing systems engineering: a unified approach to manufacturing technology, production management and industrial economics. Routledge; 2017.

26. Khitrov EG, Andronov AV. Bearing floatation of forest machines (theoretical calculation). In IOP Conference Series: Materials Science and Engineering. 2019; 695(1): 012020).

27. Ivanov V, Stepanishcheva M, Khitrov E, Iliushenko D. Theoretical model for evaluation of tractive performance of forestry machine's wheel. International Multidisciplinary Scientific GeoConference: SGEM: Surveying Geology \& mining Ecology Management. 2018; 18: 997-1003.

28. Papunin AV, Belyakov VV, Makarov VS. The study of the profile passability all-terrain vehicles with a wheel formula $6 x 6$ full mass $0.3,0.75,2$ tons. In IOP Conference Series: Materials Science and Engineering. 2020; 709(4): 044029.

29. Larin VV. Methods for predicting the traction capacity of multi-axle wheeled vehicles: Abstract of Thesis for Doctor of Technical Sciences. Moscow; 2007.

30. Volskaia VN, Zhileykin MM, Zakharov AY. Mathematical model of rolling an elastic wheel over deformable support base. In IOP Conference Series: Materials Science and Engineering. 2018; 315(1): 012028.

31. Abbas D, Handler RM. Life-cycle assessment of forest harvesting and transportation operations in Tennessee. Journal of Cleaner Production, 2018; 176: 512-520. https://doi.org/10.1016/i.jclepro.2017.11.238

32. Kogler C, Rauch P. Discrete event simulation of multimodal and unimodal transportation in the wood supply chain: a literature review. Silva Fenn. 2018; 52(4): 29. https://doi.org/10.14214/sf.998

33. Cambi M, Giannetti F, Bottalico F, Travaglini D, Nordfjell T, Chirici G, Marchi E. Estimating machine impact on strip roads via close-range photogrammetry and soil parameters: a case study in central Italy. iForest-Biogeosciences and Forestry. 2018; 11(1): 148. https://doi.org/10.3832/ifor2590010

34. Lurie KA, Cherkaev AV. Effective Characteristics of Composite Materials and the Optimal Design of Structural Elements. In Topics in the mathematical modelling of composite materials (pp. 175-271). Birkhäuser, Cham; 2018. https://doi.org/10.1007/9783-319-97184-1_7

35. Janulevičius A, Gurevičius P. Impact of the inflation pressure of the tires on lead of front drive wheels and movement resistance force of tractors. Transport. 2019;34:628-638.

https://doi.org/10.3846/transport.2019.11233

36. Abele S. Diagnostic problem-solving process in professional contexts: Theory and empirical investigation in the context of car mechatronics using computer-generated log-files. Vocations and Learning. 2018;11:133-159. https://doi.org/10.1007/s12186-017-9183-x

37. Saarilahti M. Development of a protocol for ecoefficient wood harvesting on sensitive sites (ECOWOOD). Dynamic terrain classification. University of Helsinki, Department of Forest Resource Management; 2002. 
38. Agathokleous E, Saitanis CJ, Wang X, Watanabe M, Koike T. A review study on past 40 years of research on effects of tropospheric $\mathrm{O} 3$ on belowground structure, functioning, and processes of trees: a linkage with potential ecological implications. Water, Air, \& Soil Pollution. 2016; 227(1): 33. https://doi.org/10.1007/s11270-015-2715-9

39. Han SK, Han HS, Page-Dumroese DS, Johnson LR. Soil compaction associated with cut-to-length and whole-tree harvesting of a coniferous forest. Canadian Journal of Forest Research. 2009; 39: 976989.

40. Wallbrink PJ, Roddy BP, Olley JM. A tracer budget quantifying soil redistribution on hillslopes after forest harvesting. Catena. 2002; 47: 179-201.

41. Cambi M, Grigolato S, Neri F, Picchio R, Marchi E. Effects of forwarder operation on soil physical characteristics: a case study in the Italian alps. Croatian Journal of Forest Engineering: Journal for Theory and Application of Forestry Engineering. 2016; 37: 233-239.

42. Gondard H, Romane F, Aronson J, Shater Z. Impact of soil surface disturbances on functional group diversity after clear-cutting in Aleppo pine (Pinus halepensis) forests in southern France. Forest Ecology and Management. 2003; 180: 165-174.

43. Solgi A, Naghdi R, Tsioras PA, Ilstedt U, Salehi A, Nikooy M. Combined Effects of Skidding Direction, Skid Trail Slope and Traffic Frequency on Soil Disturbance in North Mountainous Forest of Iran. Croatian Journal of Forest Engineering: Journal for Theory and Application of Forestry Engineering. 2017; 38: 97-106.

44. Deconchat M. Effects of logging techniques on the soil surface. Annals of Forest Sciences. 2001; 58: 653-661.

Received 2020-03-05

Accepted 2020-05-25

Available online 2020-05-26

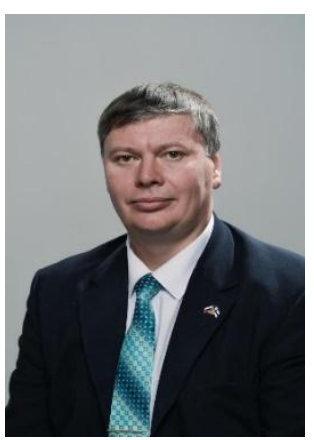

Igor GRIGOREV - Doctor

of Technical Sciences,

Professor of the Department

of Technology and

Equipment of Forest

Complex, Yakut State

Agricultural Academy,

Yakutsk, Russian

Federation. Field of

research: logging and

reforestation machinery, equipment and procedures

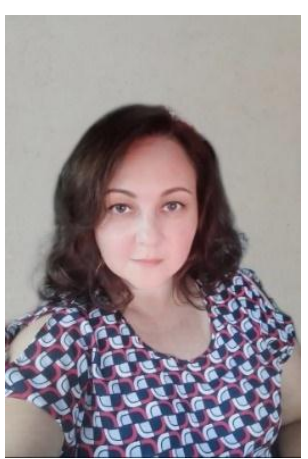

and Equipment of Forest Complex, Yakut State Agricultural Academy, Yakutsk, Russian Federation. Field of research: timber production; wood modification; the use of wood as energy; environmental safety of timber harvesting and processing facilities; wood chemical industry; and utilization of non-timber forest products

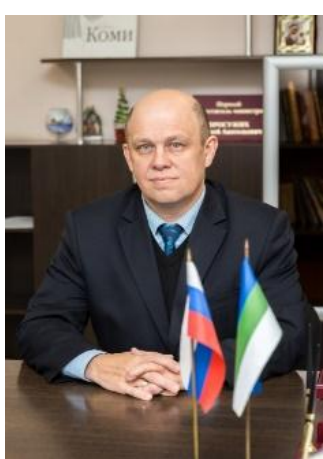

Alexey PROSUZHIH Senior Lecturer of the Department of Logging Technology and Machines, Ukhta State Technical University, Ukhta, Russian Federation. Field of research: timber production equipment and technologies, overland forestry vehicles

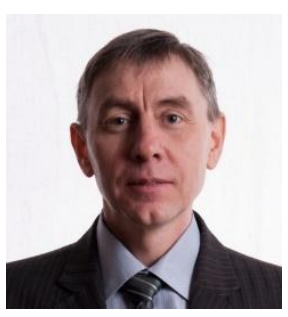

Igor KRUCHININ Doctor of Technical Sciences, Professor of the Department of Transport and Road Construction, Ural State Forestry University, Ekaterinburg, Russian Federation. Field of research: construction and operation of forest roads; research of road building materials; forest transport; winter highways

Dmitry SHAKIRZYANOV

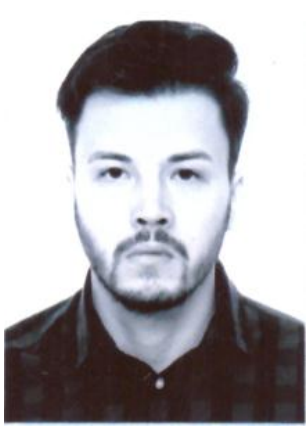

- Senior Lecturer of the Department of Engineering of Technological Machines and Equipment, Ukhta State Technical University, Ukhta, Russian Federation. Field of research: forest road design, construction, maintenance

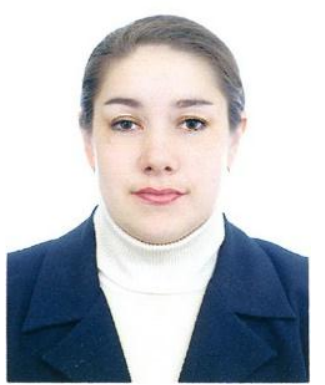

Viktoria SHVETSOVA Candidate of Technical Sciences, Associate Professor of the Department of Descriptive Geometry and Engineering Graphics, SaintPetersburg State University Architecture and Civil Engineering, SaintPetersburg, Russian Federation Field of research: three-dimensional models of hardscape elements 


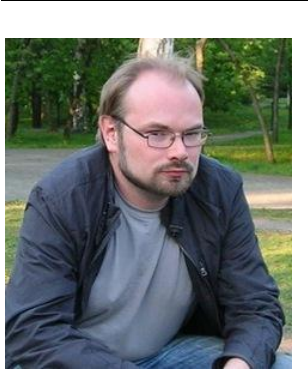

Oleg MARKOV

Candidate of Technical

Sciences, Assistant professor

of the Department of

General Technical Subjects,

Federal State Budget

Educational Institution of

Higher Education

"Petrozavodsk State

University", Petrozavodsk,

Russian Federation

Field of research:

technology and equipment

for timber harvest and

maintenance at landing

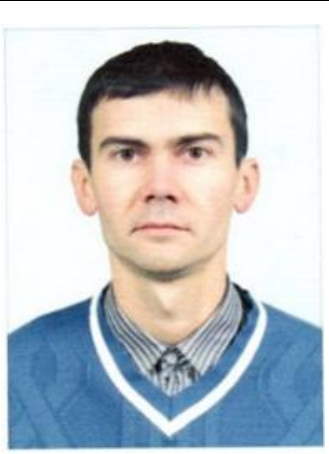

Sergey EGIPKO

Candidate of technical

Sciences, professor of the

Department Machines

Environmental Engineering,

Don State Agrarian

University, Novocherkassk,

Russian Federation. Field of

research: technologies and

means for mechanizing land preparation (agricultural

bush cleaning, tree stump removal, boulder removal, etc.) 